Long-term outcomes for Transobturator Tension Free Vaginal Tapes in Women with Urodynamic Mixed Urinary Incontinence

Authors:

Dr Mohamed Abdel-Fattah, MD, FRCOG.

Senior Clinical Lecturer/ Consultant Urogynaecologist - University Of Aberdeen

Gabriel Cao, B.Sc.

Medical student - University of Aberdeen

Dr Alyaa Mostafa, MD

Research Fellow - University of Aberdeen

- Corresponding Author: Dr M. Abdel-Fattah

Senior Lecturer/ Consultant Urogynaecologist

Division of Applied Health Sciences, University of Aberdeen

Address: Second Floor, Aberdeen Maternity Hospital, Foresterhill, Aberdeen, AB25 2ZD

Tel: 01224438424

E-mail: m.abdelfattah@abdn.ac.uk

Article Word Count: 2355 Words

Abstract Word Count: 240 words.

Key words: Transobturator tapes; Mid-urethral slings; Tension free vaginal tape; Urinary incontinence; Stress urinary incontinence. 


\section{Acknowledgments:}

We thank Dr D. Karmakar (Research Fellow - University of Aberdeen) for sending out the questionnaires and collating the responses. We thank Lindsey Grant for performing the independent data-entry cross-check. A special gratitude goes to all the participants whose excellent co-operation over the years made this study successful.

\section{Authors contributions:}

For this long-term study:

- $\quad$ Dr (s) Mohamed Abdel-fattah (MAF) \& Alyaa Mostafa (AM) conceived the idea; obtained funding; secured the ethics and institutional approvals.

- Data acquisition and data collection were performed by Dr. D. Karmakar (DK)

- Gabriel Cao (GC) was responsible for data entry and data analysis.

- $\quad$ AM and Lindsey Grant (LG) performed 100\% cross-checking of the data entry.

- GC arranged review of the statistics analysis plan with the statistics clinic in University of Aberdeen

- $\quad$ AM supervised the data analysis.

- GC and MAF wrote the manuscript

- All authors critically reviewed the manuscript and approved it

- All authors take full responsibility for the integrity of the study and the data presented.

\section{Disclosure of interests:}

- Dr Abdel-Fattah (MAF) has previously delivered paid lectures and/or training courses for Bard, Coloplast, AMS, Pfizer and Astellas. He received travel grants from different pharmaceutical companies to attend medical conferences in the past. University of Aberdeen received research grant from Coloplast in 2009.

- Dr Alyaa Mostafa (AM) received travel award from the International Continence Society (ICS) to attend the ICS annual conference in 2012.

- Gabriel Cao (GC) received a travel award from UKCS to attend the UKCS annual conference in 2016.

Funds: The initial phase of this study (up-to 3 years follow-up) was funded by the Henry Smith Charity. Dr D. Karmakar was funded by IUGA Clinical Fellowship Grant 2014. 


\title{
Long-term outcomes for Transobturator Tension Free Vaginal Tapes in Women with Urodynamic Mixed Urinary Incontinence
}

\begin{abstract}
Aims: To assess the long-term patient reported outcomes following TO-TVT in women with urodynamic mixed urinary incontinence (MUI).
\end{abstract}

Methods: A secondary analysis of the 9-year follow-up of the E-TOT study: 341 women with predominant SUI symptoms were randomised to undergo either inside-out or outside-in TO-TVT between April 2005 and April 2007. 48 women had preoperative Urodynamic MUI and were available for 9-year follow-up.

Primary outcome was the patient-reported success rate defined as Very/Much improved on Patient's Global Impression of Improvement (PGI-I). Secondary outcomes included impact on women's quality of life; sexual function; OAB symptoms and late adverse events. Statistical analysis was performed using SPSS v.23.

Results: 48 women completed the 9-year follow-up, with adjusted response rate of $63 \%$. The success, based on the PGI-I was $64.6 \%(n=31)$, with a further $14.6 \%(n=7)$ who reported “improved”. There was no significant difference between groups (OR 1.11; 95\%CI 0.33, 3.70; $\mathrm{p}>0.999$ ). Clinically significant improvement in QoL was found in 85.3\%. Cure of urgency and UUI was reported by 35 and $41 \%$ while worsening was reported in $6.5 \%$ and $2.3 \%$ respectively. One patient reported chronic groin/leg pain. The small sample size and the sizeable loss to follow-up are limitations in this study.

Conclusions: this is the first study to report the long-term outcomes of TO-TVT in women with urodynamic MUI; TO-TVT is associated with a good and sustained patient-reported success rate in women with MUI up to 9-years follow-up. 


\section{Introduction}

The unprecedented growth of the elderly population in the western world highlights the importance of studying the long-term outcomes of the interventions used for treatment of chronic conditions, including Urinary Incontinence (UI). In 2016, a large epidemiology study in the USA ${ }^{1}$ showed prevalence in UI of $19-26 \%$ and increasing with age; this was most apparent for urgency urinary incontinence (UUI) and mixed urinary incontinence (MUI). Interestingly, the prevalence of stress urinary incontinence (SUI) did not seem to increase with age in this study.

UI is associated with a negative impact on a woman's social, physical and psychological wellbeing, leading to embarrassment, low self-esteem, and negative effects on the productivity of working women. In extreme cases, patients reported avoiding employment; $60 \%$ avoided going away from home, and 50\% avoided sexual activity ${ }^{2}$. Women with MUI are twice as likely to be bothered by their symptoms as compared to those with SUI alone ${ }^{3}$.

Management of women with MUI is relatively more difficult, as it involves addressing both the SUI and overactive bladder (OAB) symptoms. Conservative management is usually the first line, including pelvic floor muscle training, bladder retraining and pharmacological treatment. If the above fails, surgery for SUI may be contemplated in women with predominant SUI symptoms; a number of options are usually discussed with the patient including mid-urethral slings (MUS) ${ }^{4}$. Transobturator tension-free vaginal tapes (TO-TVT) have been described in 2001 and $2003^{5,6}$ and have rapidly gained wide popularity among surgeons due to the avoidance of the blind retro-pubic pathway. It was also hypothesised that TO-TVT could be preferred in women with MUI compared to retro-pubic tension-free vaginal tapes (RP-TVT) due to the more horizontal position of the tape and consequently, less postoperative OAB symptoms. Botros et $\mathrm{al}^{7}$ compared RP-TVT vs TO-TVT in 276 
women; and showed significantly lower rates of de-novo urgency incontinence and/ worsening of pre-existing urgency with TO-TVT with no significant difference in SUI cure rates. However, concerns were raised on the associated risk of chronic groin pain with TOTVT.

There is a paucity of data on the long-term outcomes of TO-TVT. In the UK, the National Institute for Health and Clinical Excellence (NICE), the Cochrane review in 2015, and most recently the European review (SCENIHR) on surgical meshes in urogynaecological surgery ${ }^{4,8,9}$ have all highlighted the lack of long-term outcomes data for MUS in general and TO-TVT in particular. They emphasized the importance of directing future research to address this significant gap in the literature. This study helps to bridge this gap in the literature, and follows up on the previously reported 1-year and 3-year outcomes of women with MUI from the E-TOT study ${ }^{10,11}$.

\section{Materials and Methods}

This is a secondary analysis of the E-TOT study, a prospective single-blinded randomised controlled trial performed in the period of April 2005 and April 2007. A total of 341 women were recruited and randomly assigned to undergo either TVT-O ${ }^{\mathrm{TM}}$ (Ethicon Inc., Somerville, NJ, USA) for the Inside-out approach or TOT-ARIS ${ }^{\circledR}$ (Coloplast Corp., Minneapolis, MN, USA) for the Outside-in approach. The procedures were performed as originally described ${ }^{5,6}$ under general anaesthesia. Eighty-three women were identified to have pre-operative urodynamic MUI with predominant SUI symptoms and are the basis of this analysis as one single cohort. It is our routine clinical practice that women with MUI would have their OAB symptoms controlled/improved on conservative/pharmacological treatment before embarking on surgical treatment of SUI; women would then been given the option to discontinue treatment at time of surgery to monitor the response. Exclusion criteria included 
concomitant surgery, refractory OAB symptoms, advanced pelvic organ prolapse ( $\geq$ stage 2), and neurological conditions such as multiple sclerosis. Randomisation and allocation concealment were previously described ${ }^{10,11}$. Ethical approval was obtained from South Glasgow Research Ethics Committee for this long-term follow-up.

Pre-operative assessment included a detailed history, pelvic examination, and urodynamic assessment. Patients completed a set of validated questionnaires that included the King's Health Questionnaire (KHQ), Birmingham Bowel and Urinary Symptom Questionnaire-22 (BBUSQ-22), and Pelvic Organ Prolapse/Incontinence Sexual Function Questionnaire (PISQ-12) $)^{12-14}$. At one, three and nine years follow-up, women completed the above questionnaires and in addition, the Patient Global Impression of Improvement (PGI-I) ${ }^{15}$, the International Consultation on Incontinence Questionnaire-Short form (ICIQ-SF) ${ }^{16}$ and questions on further continence surgery and adverse events.

Outcome measures: The primary outcome measured was the patient-reported success rate defined as "very much improved" or "much improved" on the PGI-I, with all the other five responses classified as unsuccessful. In addition, all women who received further continence surgery were considered as failures. Secondary outcomes included improvement in quality of life (QoL) ( $\geq 18$ points improvement in KHQ score) ${ }^{17}$, impact on sexual function (change in PISQ-12 score), impact on pre-operative urgency and urgency incontinence (cure was defined as $\geq 2$ point improvement on the relevant BBUSQ-22 questions) and late adverse events such as groin/thigh pain and mesh erosions.

Statistical analysis was performed using SPSS version 23. Chi-squared or Fisher's exact tests were used to compare categorical variables. Within-group comparisons of KHQ scores and PISQ-12 scores were analysed using the Wilcoxon signed rank test while between-group comparisons were analysed using the Mann-Whitney U test. The results of the 
PGI-I at 9-year follow-up were compared to that of 3-year and 1-year follow-ups using McNemar's test, at the Bonferroni corrected significant level of 0.025. All other statistical analyses were performed at a 5\% significance level. Intention-to-treat (ITT) analysis will be presented for the primary outcome with/ without considering women who underwent further continence surgery as failures. Multiple sensitivity analyses were performed for those who were lost to follow-up.

\section{Results}

Eighty-three women with pre-operative urodynamic MUI and predominant SUI symptoms were randomised; 7 women were excluded (deceased $n=2$ and withdrawn $n=5$ ); 48 women completed the follow-up at nine years (Outside-in $n=29$ vs. Inside-out $n=19$ ); adjusted response rate of 63\% (Figure 1). The baseline characteristics of the patients with MUI are presented in Table 1.

Patient-reported success rate: On considering women who had further continence surgery as failures, the corrected patient-reported success rate was $64.6 \%$ with a further $14.6 \%$ $(n=7)$ who reported “improved". There was no significant difference between groups (Outside-in 65.5\% vs Inside-out 63.2\%, OR 1.11, 95\% CI 0.33 to 3.70, p>0.999) (Table 2). A sensitivity analysis was performed assuming the women lost to follow-up as failures, as successes, and based on their last observation carried forward (LOCF) and is presented in Table 2.

There was a trend towards a drop in the patient-reported success rate over the years (Figure 2). Comparison of the patient-reported success, and using Bonferroni corrected significance level of $\mathrm{p} \leq 0.025$ showed insignificant reduction with time: 1 vs 9 years $74.7 \%$ vs. 64.6\%; $\mathrm{p}=0.031$, and 3 vs 9 years were $73.8 \%$ vs. $64.6 \%$; $=0.039$. The patient-reported 
success rate in women with MUI was not significantly different compared to women with pure urodynamic SUI in the same cohort ${ }^{18}(64.6 \%$ vs $73.8 \%$, OR 0.65 , 95\% CI $0.33,1.29$, $\mathrm{p}=0.273)$.

Impact on OAB symptoms: At the 9-year follow-up, 46 and 44 women responded to the BBUQ-22 questions on urgency \& UUI respectively. Compared to baseline; $34.8 \%$ $(n=16)$ were cured of urgency, while $58.7 \%(n=27)$ had persistent urgency, and $6.5 \%(n=3)$ had worsening urgency. $40.9 \%(n=18)$ were cured of UUI, while $56.8 \%(n=25)$ had persistent UUI, and 2.3\% $(\mathrm{n}=1)$ had worsening UUI. There was no association between the type of TOTVT procedure and the impact on urgency $(\mathrm{p}=0.629)$ or on UUI $(\mathrm{p}=0.360)$ symptoms. There was a trend towards a drop in the OAB cure rates over the 9-years (Figure 2). Women with cured Urgency had significantly higher patient-reported success rate compared to those with persistent/worsened symptoms (87.5\% vs. $50 \%$, $\mathrm{p}=0.029)$.

Late adverse events: Chronic groin/ leg pain was reported in one patient (2\%) at nine years in the Outside-in group. There were no reports of mesh extrusion or erosion in this group.

Impact on QoL: Thirty-four women (70.8\%) completed the KHQ questionnaires at 9year follow-up. There were statistically significant decreases (improvement) in scores from baseline in all domains of the KHQ, with the exception of general health (Table 3). Clinically significant improvement in QoL ( $\geq 18$ point improvement in total KHQ score) was found in 85.3\% (Outside-in 86.4\% vs Inside-out 83.3\%; OR 0.79; 95\%CI 0.11, 5.53; p>0.999). However, based on an improvement score of $\geq 10$ point improvement ${ }^{19}, 91.2 \%$ had a clinically significant improvement in QoL (Outside-in 90.9\% vs Inside-out 91.7\%, OR 1.10; 95\% CI 0.09, 13.55; $\mathrm{p}>0.999)$. 
Impact on sexual function: Twenty-one women (43.8\%) were sexually active and completed the PISQ-12 sexual function questionnaire at the 9-year follow-up, however only 16 were sexually active at both baseline and 9-year follow-up time points. $62.5 \%(n=10)$ showed an increase of $\geq 1$ point in PISQ-12 scores, indicating an improvement of sexual function (Table 3).

\section{Discussion:}

This is the longest follow-up study reporting on the long-term outcomes of TO-TVT on women with MUI. Results showed patient-reported success rate of $64.6 \%$ at median of 9years follow-up with further $14.6 \%$ reporting improvement. It was reassuring to see that the results did not change significantly on sensitivity analysis using last observation carried forward. In-addition, $85.3 \%$ of women reported clinically significant improvement in their QoL which gives us more confidence in the results. It was reassuring to see that $34.8 \%$ of women were cured of their pre-operative urgency and $40.9 \%$ were cured of UUI, while a small proportion (6.5\% and 2.3\%) had worsening symptoms respectively; women with cured OAB symptoms had significantly higher patient-reported success rate on PGI-I.

Our patient-reported success rate was comparable to other studies in the literature reporting on long-term outcomes of TO-TVT. Costantini et $\mathrm{al}^{20}$ compared TO-TVT vs RPTVT in an RCT; 31 women (66\%) in the TO-TVT group had baseline MUI and showed patient-reported success rates of $77.4 \%$ and $64.5 \%$ at three and six years respectively. Similarly, Zhang et al. reported the 7-year outcomes in their RCT comparing RP-TVT vs. TO-TVT procedures in women with SUI; the success rate for the TO-TVT was $69.4 \%^{21}$, however they did not report the success rate in the subgroup of women with MUI. Heinonen et $\mathrm{al}^{22}$ assessed 139 women who underwent Outside-in TO-TVT with a mean follow-up of 6.5 years; $76 \%$ of women with baseline MUI reported satisfaction with their surgical outcomes. 
Secondary outcomes in our study were between-group comparisons. Our results showed no significant difference between the Outside-in and Inside-out TO-TVT; this pertained on multiple sensitivity analyses. These results are unique as there are no published long-term trials comparing these procedures in women with MUI. One retrospective study by Chun et $\mathrm{al}^{23}$ reported the 7-year outcomes in women with SUI and showed significantly higher success rates in the Outside-in group (Outside-in 95.7\% vs. Inside-out 78.4\%; p<0.001). However, the lack of randomisation and the retrospective nature allows for selection and recall bias respectively.

The success rate in our study declined over the years, from $74.7 \%$ to $73.8 \%$ to $64.6 \%{ }^{10,11}$; the decline was not found to be statistically significant. The results are in line with the Cochrane review by Ford et al. ${ }^{8}$, which showed a decreasing success rate of MUS in women with SUI over the years. Similarly, long-term follow-up of RP-TVT vs. autologous fascial slings (AFS) in women with SUI showed deterioration of success at one versus ten years (TVT: $93 \%$ to $73 \%$ and AFS: $90 \%$ to $75.4 \%$ ). However, unlike the E-TOT, the latter RCT used a looser definition of success ${ }^{24}$.

Only one systematic review and meta-analysis reported on the effectiveness of MUS in women with MUI. However, they only found relatively small trials that reported up to medium-term outcomes (mean $34.9 \pm 22.9$ months) ${ }^{25}$. The authors reported that MUS are associated with an overall success rate of $56.4 \%$ in women with MUI and were more effective in treating the stress component (85-97\% success) than the urgency component (28$85 \%$ success).

Our results showed that the majority of women still reported OAB symptoms at 9-years. It's well recognized that $\mathrm{OAB}$ symptoms tend to wax and wane and the incidence increase with age ${ }^{26}$. Jahanlu and Hunskaar ${ }^{27}$ assessed 1274, originally continent, women at age of 41- 
45 years over 10 years period and showed that $40 \%$ developed new onset UI; $50 \%, 18.3 \%$ and $20.3 \%$ for stress (SUI), urgency (UUI) and mixed urinary incontinence (MUI), respectively. Hence on assessing urgency at long-term follow-up studies, it can be difficult to ascertain if it's related to the MUS or the advancing age or is a progression of an underlying pathology.

Reassuringly, $35 \%$ and $41 \%$ of women achieved our pre-defined definition of cure for urgency and UUI at median of 9-years respectively ( $\geq 2$ points improvement on the urgency questions for the BBUQ-22). Understandably, women with cured OAB symptoms had significantly higher patient-reported success rates on PGI-I. Our results were lower than Lee et al. $^{28}$, who showed $65.5 \%$ and $63.6 \%$ resolution rate of urgency and UUI respectively at 50month follow-up, following Outside-in TO-TVT. In contrast, Yonguc et al. assessed 48 women with MUI and reported that only 5.5\% had resolution of UUI at 5-years follow-up ${ }^{29}$. Upon closer analysis, it seems that they had a stringent and unique definition of cure; a score of zero on the ICIQ-SF and discontinuation of anti-cholinergic medication. It is well recognised that ICIQ-SF has no normal values and success is usually defined by mean change in scores postoperatively.

Jain et $\mathrm{al}^{25}$ described a trend of decreasing cure of OAB over time, with $81-100 \%$ cure of UUI component at 12 months compared to $35-43 \%$ at 38 months follow-up. Our findings reflect a less sharp decline: $56.2 \%, 51.5 \%$ and $35 \%$ at 1,3 and 9 years respectively. It's worth noting that $\mathrm{OAB}$ symptoms are common and have been reported in up-to $94 \%$ of women with a diagnosis of urodynamic SUI, therefore OAB symptoms with urodynamic SUI may have different outcomes compared to those for urodynamic MUI in this study.

Our study used the PGI-I as the primary outcome as it provides a robust, validated and more global review of the treatment outcome, and more fully encompassing the range of 
benefits and potential harms of the treatment ${ }^{15}$. Several studies have established its validity to assess disease severity, bother and improvement after treatment in women with stress urinary incontinence and refractory overactive bladder. Two most recently reported clinical trials on 10-years outcomes following surgical treatment of SUI in women utilised PGI-I in their primary patient-reported outcomes ${ }^{30,31}$.

The long-term impact of any surgical procedure on QoL can be difficult to assess due to the potential development of confounding factors over the years. Nevertheless, our study used disease-specific questionnaires which showed clinically significant improvement in QoL in $85 \%$ of respondents at 9-year follow-up. Similar results were seen at 1-year and 3-year follow-ups. Comparisons of improvement of QoL with the available literature proved difficult due to the differences in methods of assessing QoL by various studies. However, the Cochrane review ${ }^{8}$ reported that all included studies reported an improvement in womens' QoL following TO-TVTs.

Our results on the sexual function assessment are unlikely to be of clinical significance, knowing the small number of women in this analysis. Nevertheless, Zhang et al. ${ }^{21}$ reported similar results with no significant improvement in sexual function after a mean of 95 months following TO-TVT operation.

\section{Strengths and limitations}

This study has a number of strengths: the longest reported follow-up on women with MUI; the follow-up by postal questionnaire eliminates the risk of detection bias; and the use of validated questionnaires for assessing the outcomes. However, we acknowledge the limitations of the results; one of which is the sizeable loss to follow-up despite attempts to minimise attrition. As a secondary analysis of a larger RCT, the sample size was not 
adequately powered to detect a difference between the two types of TO-TVT procedures and leaves it vulnerable to a type II error. Nevertheless, the results will be quite important for relevant meta-analyses. The lack of objective assessment can be seen as a limitation; however the research community is increasingly recognising patient-reported outcome measures as more clinically relevant ${ }^{32}$.

\section{Conclusion}

This is the first study to report the long-term outcomes of TO-TVT in women with urodynamic MUI; TO-TVT operations are associated with a good and sustained patientreported success rate in women with MUI, up to nine years of follow-up. $40 \%$ of women were cured of urgency incontinence. 
References:

1. Komesu YM, Schrader RM, Ketai LH, Rogers RG, Dunivan GC. Epidemiology of mixed, stress, and urgency urinary incontinence in middle-aged/older women: the importance of incontinence history. Int Urogynecol J 2016;27:763-72.

2. Norton PA, MacDonald LD, Sedgwick PM, Stanton SL. Distress and delay associated with urinary incontinence, frequency, and urgency in women. BMJ 1988;297:1187-9.

3. Minassian VA, Devore E, Hagan K, Grodstein F. Severity of urinary incontinence and effect on quality of life in women by incontinence type. Obstet Gynecol 2013;121:1083-90.

4. Urinary Incontinence: The management of Urinary Incontinence in Women. Manchester (UK): 2013. National Institute for Health and Clinical Excellence(NICE). (, september, at http://www.nice.org.uk/).

5. Delorme E. Transobturator urethral suspension: mini-invasive procedure in the treatment of stress urinary incontinence in women. Prog Urol 2001;11:1306-13.

6. de Leval J. Novel surgical technique for the treatment of female stress urinary incontinence: transobturator vaginal tape inside-out. Eur Urol 2003;44:724-30.

7. Botros SM, Miller JJ, Goldberg RP, et al. Detrusor overactivity and urge urinary incontinence following trans obturator versus midurethral slings. Neurourol Urodyn 2007;26:42-5.

8. Ford AA, Rogerson L, Cody JD, Ogah J. Mid-urethral sling operations for stress urinary incontinence in women. Cochrane Database Syst Rev 2015;7:CD006375.

9. Opinion on: The safety of surgical meshes used in urogynecological surgery 2015. Scientific Committee on Emerging and Newly Identified Health Risks (SCENIHR).(Accessed 3 December, 2015, at http://ec.europa.eu/health/scientific_committees/consultations/public_consultations/scenihr_c onsultation_27_en.htm). 
10. Abdel-fattah M, Mostafa A, Young D, Ramsay I. Evaluation of transobturator tensionfree vaginal tapes in the management of women with mixed urinary incontinence: one-year outcomes. Am J Obstet Gynecol 2011;205:150.e1,150.e6.

11. Abdel-Fattah M, Hopper LR, Mostafa A. Evaluation of transobturator tension-free vaginal tapes in the surgical management of women with mixed urinary incontinence: 3-years outcomes of a randomised controlled trial. J Urol 2014;191;114-119.

12. Kelleher CJ, Cardozo LD, Khullar V, Salvatore S. A new questionnaire to assess the quality of life of urinary incontinent women. Br J Obstet Gynaecol 1997;104:1374-9.

13. Hiller L, Bradshaw HD, Radley SC, Radley S. A scoring system for the assessment of bowel and lower urinary tract symptoms in women. BJOG 2002;109:424-30.

14. Rogers RG, Coates KW, Kammerer-Doak D, Khalsa S, Qualls C. A short form of the Pelvic Organ Prolapse/Urinary Incontinence Sexual Questionnaire (PISQ-12). Int Urogynecol J Pelvic Floor Dysfunct 2003;14:164,8; discussion 168.

15. Yalcin I, Bump RC. Validation of two global impression questionnaires for incontinence. Am J Obstet Gynecol 2003;189:98-101.

16. Avery K, Donovan J, Peters TJ, Shaw C, Gotoh M, Abrams P. ICIQ: a brief and robust measure for evaluating the symptoms and impact of urinary incontinence. Neurourol Urodyn 2004;23:322-30.

17. Abdel-fattah M, Hasafa Z, Mostafa A. Correlation of three validated questionnaires for assessment of outcomes following surgical treatment of stress urinary incontinence in women. Eur J Obstet Gynecol Reprod Biol 2011;157:226-9.

18. Karmakar D, Mostafa A, Abdel-fattah M. Long-Term Patient-Reported Outcomes Of Transobturator Tapes In Women With Stress Urinary Incontinence. Un-published.

19. Kelleher CJ, Pleil AM, Reese PR, Burgess SM, Brodish PH. How much is enough and who says so? BJOG 2004;111:605-12. 
20. Costantini E, Lazzeri M, Zucchi A, Di Biase M, Porena M. Long-term efficacy of the transobturator and retropubic midurethral slings for stress urinary incontinence: singlecenter update from a randomized controlled trial. European urology 2014;66:599-603.

21. Zhang Z, Zhu $\mathrm{L}, \mathrm{Xu} \mathrm{T}$, Lang J. Retropubic tension-free vaginal tape and inside-out transobturator tape: a long-term randomized trial. Int Urogynecol J 2016;27:103-11.

22. Heinonen P, Ala-Nissila S, Raty R, Laurikainen E, Kiilholma P. Objective cure rates and patient satisfaction after the transobturator tape procedure during 6.5-year follow-up. J Minim Invasive Gynecol 2013;20:73-8.

23. Chun JY, Song M, Yoo DS, Han JY, Hong B, Choo MS. A Comparative Study of Outside-In and Inside-Out Transobturator Tape Procedures for Female Stress Urinary Incontinence: 7-Year Outcomes. Low Urin Tract Symptoms 2014;6:145-50.

24. Khan ZA, Nambiar A, Morley R, Chapple CR, Emery SJ, Lucas MG. Long-term followup of a multicentre randomised controlled trial comparing tension-free vaginal tape, xenograft and autologous fascial slings for the treatment of stress urinary incontinence in women. BJU Int 2015;115:968-77.

25. Jain P, Jirschele K, Botros SM, Latthe PM. Effectiveness of midurethral slings in mixed urinary incontinence: a systematic review and meta-analysis. Int Urogynecol J 2011;22:92332.

26. Irwin DE, Milsom I, Chancellor MB, Kopp Z, Guan Z. Dynamic progression of overactive bladder and urinary incontinence symptoms: a systematic review. Eur Urol 2010;58:532-43.

27. Jahanlu D, Hunskaar S. Type and severity of new-onset urinary incontinence in middleaged women: the Hordaland Women's Cohort. Neurourol Urodyn 2011;30:87-92. 
28. Lee JK, Dwyer PL, Rosamilia A, Lim YN, Polyakov A, Stav K. Persistence of urgency and urge urinary incontinence in women with mixed urinary symptoms after midurethral slings: a multivariate analysis. BJOG 2011;118:798-805.

29. Yonguc T, Gunlusoy B, Degirmenci T, et al. Are the outcomes of transobturator tape procedure for female stress urinary incontinence durable in long-term follow-up? Int Urol Nephrol 2014;46:1295-300.

30. Serati M, Braga A, Athanasiou S, et al. Tension-free Vaginal Tape-Obturator for Treatment of Pure Urodynamic Stress Urinary Incontinence: Efficacy and Adverse Effects at 10-year Follow-up. Eur Urol 2016; Published on-line; DOI:10.1016/j.eururo.201608.054.

31. Ulrich D, Tammaa A, Holbfer S, et al. Ten-Year Followup after Tension-Free Vaginal Tape-Obturator Procedure for Stress Urinary Incontinence. J Urol 2016;196:1201-6.

32. Scientific Advisory Committee, Royal College of Obstetricians and Gynaecologists. Patient-reported Outcome Measures in Gynaecology (PROMs) 2012; Scientific Impact Paper 31. 
Figure 1: CONSORT diagram of patients recruited and follow-up

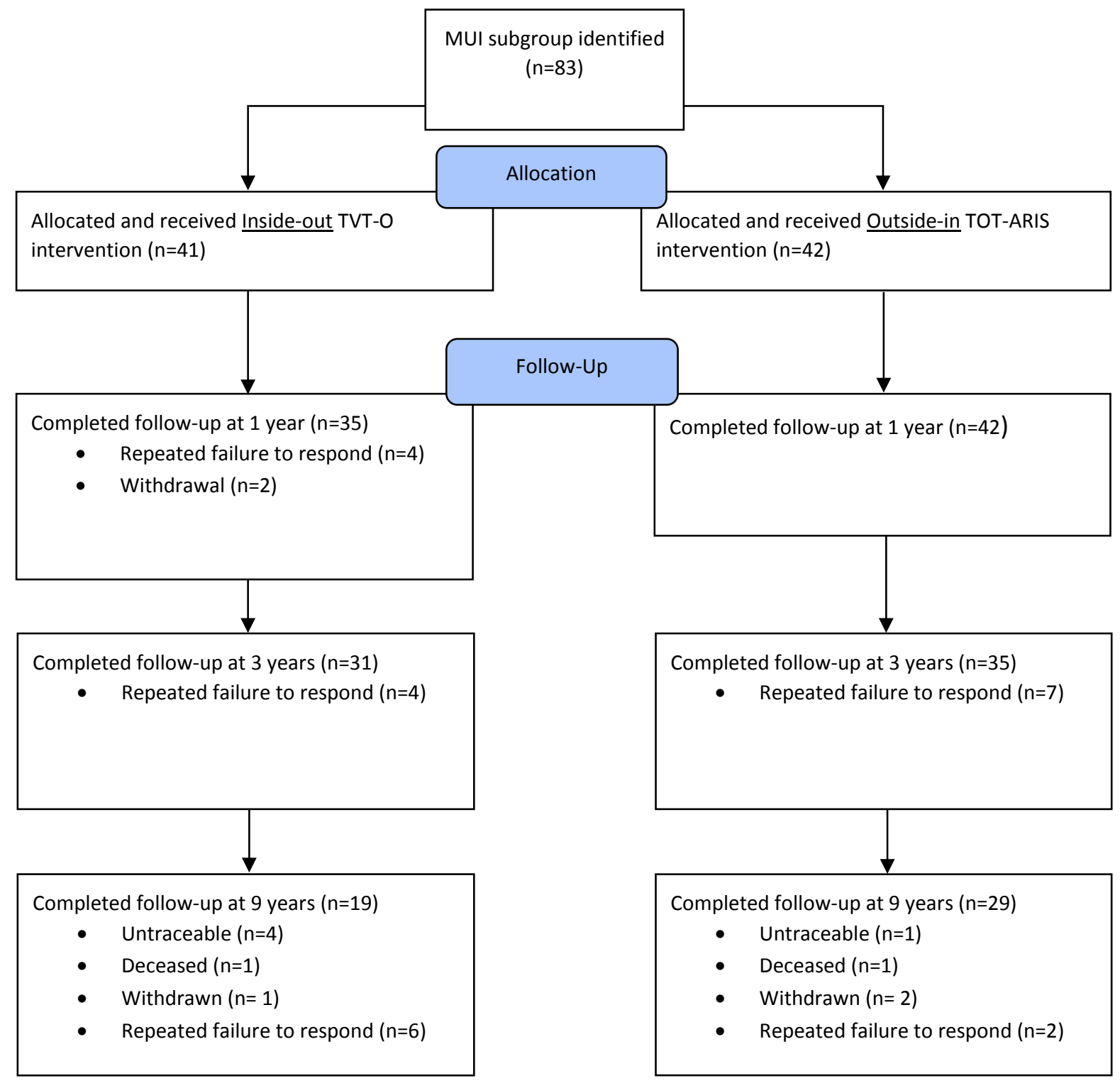


Figure 2: PGI-I success rate and OAB outcomes at 1, 3 and 9-year follow-up

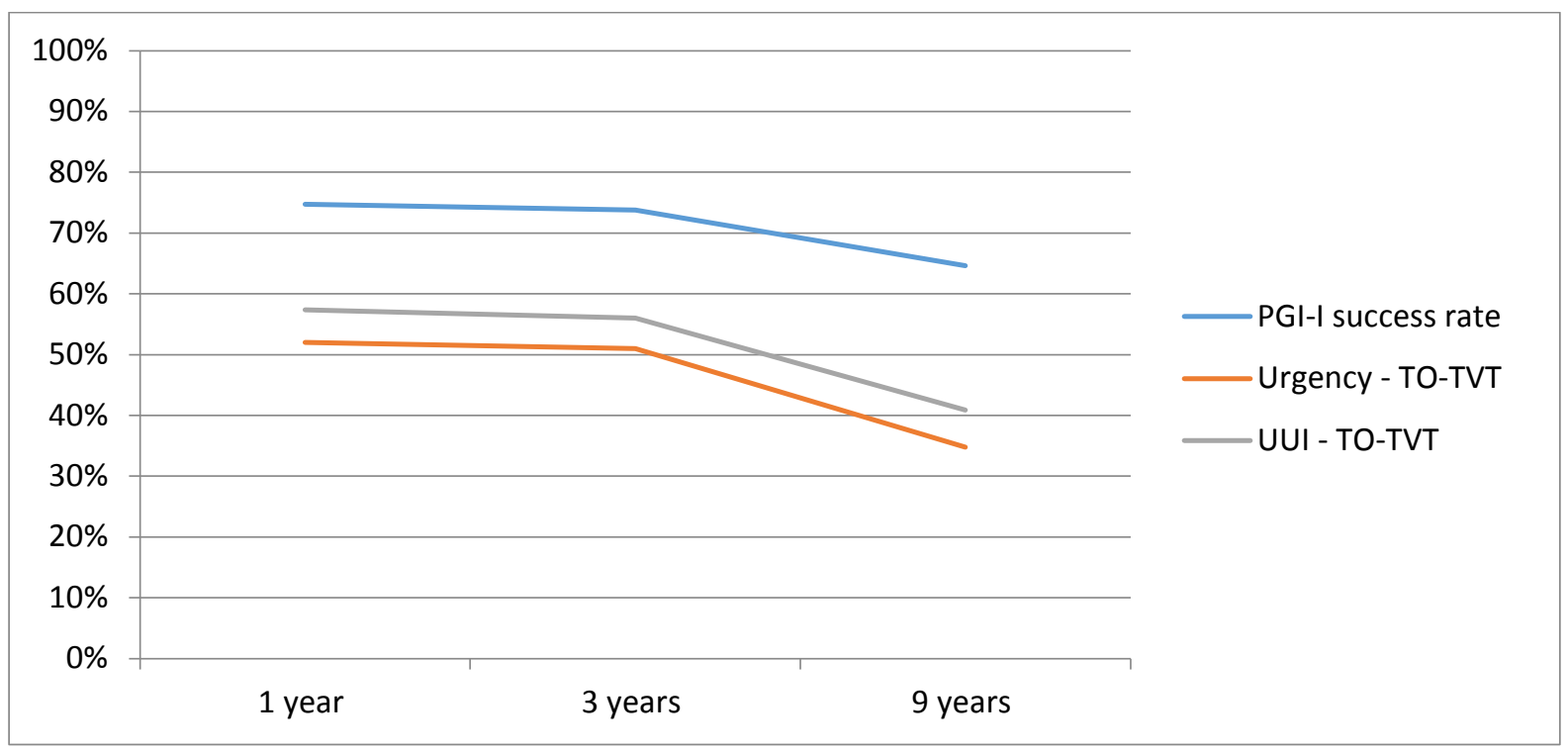


Table 1: Baseline characteristics of patients

\begin{tabular}{|l|l|l|l|l|}
\hline & Whole cohort & Outside-in & Inside-out & p-value \\
\hline Median age (IQR) & $\begin{array}{l}52.00 \\
(46.47 \text { to } 67.57)\end{array}$ & $\begin{array}{l}55.70 \\
(47.52 \text { to } 66.73)\end{array}$ & $\begin{array}{l}47.37 \\
(44.73 \text { to } 68.51)\end{array}$ & 0.287 \\
\hline Mean BMI + SD & $28.65 \pm 4.706$ & $28.97 \pm 5.130$ & $28.16 \pm 4.059$ & 0.567 \\
\hline $\begin{array}{l}\text { Previous anti- } \\
\text { muscarinics }\end{array}$ & $\begin{array}{l}12 / 48 \\
(25.0 \%)\end{array}$ & $\begin{array}{l}8 / 29 \\
(27.6 \%)\end{array}$ & $\begin{array}{l}4 / 19 \\
(21.1 \%)\end{array}$ & 0.865 \\
\hline $\begin{array}{l}\text { Previous } \\
\text { hysterectomy }\end{array}$ & $\begin{array}{l}21 / 48 \\
(43.8 \%)\end{array}$ & $\begin{array}{l}14 / 29 \\
(48.3 \%)\end{array}$ & $\begin{array}{l}7 / 19 \\
(36.8 \%)\end{array}$ & 0.629 \\
\hline $\begin{array}{l}\text { Previous anterior } \\
\text { repair }\end{array}$ & $\begin{array}{l}4 / 48 \\
(8.3 \%)\end{array}$ & $\begin{array}{l}1 / 29 \\
(3.4 \%)\end{array}$ & $\begin{array}{l}3 / 19 \\
(15.8 \%)\end{array}$ & 0.286 \\
\hline $\begin{array}{l}\text { Previous } \\
\text { incontinence } \\
\text { surgery }\end{array}$ & $\begin{array}{l}6 / 48 \\
(12.5 \%)\end{array}$ & $\begin{array}{l}3 / 29 \\
(10.3 \%)\end{array}$ & $\begin{array}{l}3 / 19 \\
(15.8 \%)\end{array}$ & 0.669 \\
\hline
\end{tabular}

Table 2: Patient-reported success at 9-year follow-up

\begin{tabular}{|c|c|c|c|c|c|}
\hline & $\begin{array}{l}\text { Total number } \\
\text { (\%) }\end{array}$ & $\begin{array}{l}\text { Outside-in } \\
\text { (\%) }\end{array}$ & $\begin{array}{l}\text { Inside-out } \\
\text { (\%) }\end{array}$ & OR $(95 \% \mathrm{Cl})$ & p-value \\
\hline PGI-I ${ }^{\#}$ & $31 / 48$ (64.6) & 19/29 (65.5) & $12 / 19(63.2)$ & $1.11(0.33,3.70)$ & $>0.999$ \\
\hline \multicolumn{6}{|c|}{ Sensitivity analysis based on PGI-I ${ }^{\#}$ for patients lost to follow-up: } \\
\hline $\begin{array}{l}\text { Last observation carried } \\
\text { forward }\end{array}$ & $47 / 77(61.8)$ & $26 / 42(63.4)$ & $21 / 35(60.0)$ & $1.16(0.46,2.92)$ & 0.945 \\
\hline $\begin{array}{l}\text { Assume all missing data } \\
\text { as failure }\end{array}$ & $31 / 83(37.3)$ & 19/42 (45.2) & $12 / 41(29.3)$ & $2.00(0.81,4.94)$ & 0.202 \\
\hline $\begin{array}{l}\text { Assume all missing data } \\
\text { as success }\end{array}$ & $66 / 83(79.5)$ & $32 / 42(76.2)$ & $34 / 41(82.9)$ & $0.66(0.22,1.94)$ & 0.625 \\
\hline
\end{tabular}


Table 3: Comparison of KHQ and PISQ-12 scores between pre-operative and 9-year follow-up and between Outside-in and Inside-out procedures

\begin{tabular}{|c|c|c|c|c|c|c|c|}
\hline & & \multicolumn{2}{|l|}{ Median (IQR) } & \multirow[t]{2}{*}{$p$-value } & \multicolumn{2}{|c|}{ Median difference (IQR) } & \multirow{2}{*}{$\begin{array}{l}\mathrm{p}- \\
\text { value }\end{array}$} \\
\hline & & Pre-op & 9-year post-op & & Outside-in & Inside-out & \\
\hline \multirow[t]{9}{*}{$\begin{array}{l}\mathrm{KHQ} \\
\text { domains }\end{array}$} & $\begin{array}{l}\text { General } \\
\text { health }\end{array}$ & $\begin{array}{l}25.00 \\
(25.00,25.00)\end{array}$ & $\begin{array}{l}25.00 \\
(0.00,50.00)\end{array}$ & 0.297 & $\begin{array}{l}0.00 \\
(0.00,18.75)\end{array}$ & $\begin{array}{l}0.00 \\
(-25.00,0.00)\end{array}$ & 0.117 \\
\hline & $\begin{array}{l}\text { Incontinence } \\
\text { impact }\end{array}$ & $\begin{array}{l}100.00 \\
(66.67,100)\end{array}$ & $\begin{array}{l}33.33 \\
(0.00,66.67)\end{array}$ & $<0.001$ & $\begin{array}{l}66.67 \\
(33.33,91.67)\end{array}$ & $\begin{array}{l}66.67 \\
(25.00,100.00)\end{array}$ & 0.944 \\
\hline & $\begin{array}{l}\text { Role } \\
\text { limitation }\end{array}$ & $\begin{array}{l}83.33 \\
(50.00,100.00)\end{array}$ & $\begin{array}{l}0.00 \\
(0.00,33.33)\end{array}$ & $<0.001$ & $\begin{array}{l}66.67 \\
(33.33,83.33)\end{array}$ & $\begin{array}{l}66.67 \\
(25.00,83.33)\end{array}$ & $\begin{array}{l}>0.99 \\
9\end{array}$ \\
\hline & $\begin{array}{l}\text { Physical } \\
\text { limitation }\end{array}$ & $\begin{array}{l}66.67 \\
(50.00,95.83)\end{array}$ & $\begin{array}{l}16.67 \\
(0.00,33.33)\end{array}$ & $<0.001$ & $\begin{array}{l}50.00 \\
(16.67,66.67)\end{array}$ & $\begin{array}{l}50.00 \\
(25.00,83.33)\end{array}$ & 0.325 \\
\hline & $\begin{array}{l}\text { Social } \\
\text { limitation }\end{array}$ & $\begin{array}{l}50.00 \\
(22.22,77.78)\end{array}$ & $\begin{array}{l}0.00 \\
(0.00,22.22)\end{array}$ & $<0.001$ & $\begin{array}{l}22.22 \\
(0.00,63.89)\end{array}$ & $\begin{array}{l}55.56 \\
(19.44,75.00)\end{array}$ & 0.303 \\
\hline & $\begin{array}{l}\text { Personal } \\
\text { limitation }\end{array}$ & $\begin{array}{l}33.33 \\
(0.00,83.33)\end{array}$ & $\begin{array}{l}0.00 \\
(0.00,0.00)\end{array}$ & 0.001 & $\begin{array}{l}16.67 \\
(0.00,66.67)\end{array}$ & $\begin{array}{l}33.33 \\
(0.00,58.33)\end{array}$ & 0.602 \\
\hline & Emotions & $\begin{array}{l}66.67 \\
(44.44,100.00)\end{array}$ & $\begin{array}{l}0.00 \\
(0.00,27.78)\end{array}$ & $<0.001$ & $\begin{array}{l}44.44 \\
(33.33,75.00)\end{array}$ & $\begin{array}{l}44.44 \\
(33.33,83.33)\end{array}$ & 0.464 \\
\hline & $\begin{array}{l}\text { Sleep/ } \\
\text { energy }\end{array}$ & $\begin{array}{l}66.67 \\
(37.50,83.33)\end{array}$ & $\begin{array}{l}25.00 \\
(0.00,50.00)\end{array}$ & $<0.001$ & $\begin{array}{l}33.33 \\
(0.00,50.00)\end{array}$ & $\begin{array}{l}33.33 \\
(16.67,50.00)\end{array}$ & 0.941 \\
\hline & $\begin{array}{l}\text { Severity } \\
\text { measure }\end{array}$ & $\begin{array}{l}83.33 \\
(66.67,91.67)\end{array}$ & $\begin{array}{l}25.00 \\
(2.08,50.00)\end{array}$ & $<0.001$ & $\begin{array}{l}58.33 \\
(27.08,68.75)\end{array}$ & $\begin{array}{l}54.17 \\
(16.67,70.83)\end{array}$ & 0.966 \\
\hline \multicolumn{2}{|c|}{ Total KHQ } & $\begin{array}{l}63.43 \\
(50.15,78.24)\end{array}$ & $\begin{array}{l}17.28 \\
(4.24,26.85)\end{array}$ & $<0.001$ & $\begin{array}{l}43.98 \\
(25.89,63.27)\end{array}$ & $\begin{array}{l}50.20 \\
(23.46,57.48)\end{array}$ & 0.885 \\
\hline \multicolumn{2}{|c|}{ Total PISQ-12 } & $\begin{array}{l}28.5 \\
(22.00,33.00)\end{array}$ & $\begin{array}{l}35.00 \\
(29.00,40.50)\end{array}$ & 0.093 & $\begin{array}{l}7.50 \\
(-0.75,14.75)\end{array}$ & $\begin{array}{l}-1.00 \\
(-4.25,8.75)\end{array}$ & 0.301 \\
\hline
\end{tabular}

